\title{
Reading decoding and comprehension in children with autism spectrum disorders: Evidence from a language with regular orthography
}

\author{
Rosa Zuccarello a,*, Francesco Domenico Di Blasi ${ }^{a}$, Marinella Zingale ${ }^{a}$, \\ Simonetta Panerai ${ }^{a}$, Maria Finocchiaro ${ }^{a}$, Grazia Trubia ${ }^{a}$, \\ Serafino Buono ${ }^{a}$, Pierluigi Zoccolotti ${ }^{\mathrm{b}, \mathrm{c}}$ \\ a IRCCS Associazione Oasi Maria SS., Unit of Pedagogy, Via Conte Ruggero 73, 94018 Troina, EN, Italy \\ ${ }^{\mathrm{b}}$ University of Rome La Sapienza, Department of Psychology, Via dei Marsi 78, 00185 Rome, Italy \\ ' IRCCS Foundation Hospital Santa Lucia, Neuropsychological Research Unit, via Ardeatina 306, 00179 Rome, Italy
}

\section{A R T I C L E I N F O}

\section{Article history}

Received 2 December 2014

Received in revised form 8 June 2015

Accepted 24 June 2015

Available online 8 July 2015

\section{Keywords:}

Reading

Comprehension

Autism spectrum disorders

Borderline functioning

\begin{abstract}
A B S T R A C T
Decoding and comprehension skills in children with autism spectrum disorders (ASD) were analysed in children native speakers of a language (Italian) with a highly regular orthography. Children with ASD were compared to children with matched intellectual functioning: a subgroup of children with ASD and borderline intellectual functioning (BIF) was compared to a subgroup of children with BIF but no signs of ASD; a subgroup of children with ASD and cognitive functioning within normal limits was compared to a group of typically developing children. Children with ASD (whether with or without BIF) showed essentially spared decoding skills in text as well as word and pseudo-word reading; this was at variance with children with BIF who, as a group, showed overall deficient decoding skills, despite considerable individual differences. By contrast, children with ASD (once again, irrespective of the presence of BIF) showed a selective impairment in reading comprehension, just like children with BIF but unlike the typically developing ones. Therefore, results are generally consistent with a profile of hyperlexia for children with ASD learning a regular orthography, as previously reported for other languages. Notably, this pattern was present irrespective of the degree of cognitive impairment, and clearly distinguished these children from those with borderline intellectual functioning but not signs of autism.
\end{abstract}

(c) 2015 Elsevier Ltd. All rights reserved.

\section{Introduction}

The autism spectrum disorders (ASD) represent a group of clinical conditions characterized by abnormal communication, impaired socialization and restricted activities and interests. These conditions can be associated to varying degrees of cognitive disabilities. The cognitive profile of individuals with ASD is complex with areas of strength in visuo-spatial, sensory-motor and memory abilities and areas of weakness in executive functions, attention, abstract reasoning, formation

\footnotetext{
* Corresponding author. Tel.: +39 0935936374; fax: +39 0935936231.

E-mail addresses: rzuccarello@oasi.en.it (R. Zuccarello), fdiblasi@oasi.en.it (F.D. Di Blasi), mzingale@oasi.en.it (M. Zingale), spanerai@oasi.en.it (S. Panerai), mfinocchiaro@oasi.en.it (M. Finocchiaro), gtrubia@oasi.en.it (G. Trubia), fbuono@oasi.en.it (S. Buono), pierluigi.zoccolotti@uniroma1.it (P. Zoccolotti).
} 
of mental prototypes and categorization (Rutter, 1983; Sigman \& Mundy, 1987; Courchesne, Lincoln, Yeung-Courchesne, Elmasian, \& Grillon, 1989).

A typical characteristic of ASD is the presence of language disorders (Schopler \& Mesibov, 1995). Early studies on language difficulties took into consideration unusual domains, such as echolalia (e.g., Kanner, 1946; Bartak, Rutter, \& Cox, 1975). More recent investigations have focused on several domains of language development, such as grammar morphology, syntax, semantics, pragmatics; they have also examined other aspects, such as phonology and phoneme-grapheme correspondence, which are critical to writing and decoding a written text (e.g., Schopler \& Mesibov, 1995).

How children with developmental disabilities can early decode a series of words has been already highlighted (Parker, 1919; Phillips, 1930) and referred to by Kanner (1943) in his first report describing childhood autism. However, it is only after Silberberg and Silberberg (1967) identified the exceptional ability to decode words (hyperlexia) in some children with developmental disorders that systematic studies on children with this special ability have taken place.

The term hyperlexia was first introduced by Silberberg and Silberberg (1967) and refers to an unusually high ability of children in decoding rather than understanding and integrating written words. Thus, in such children, the word reading ability goes beyond expectation, based on their overall cognitive and verbal functioning (Silberberg \& Silberberg, 1967, 1968-1969). However, it is not clear whether this discrepancy should be expressed by contrasting the level of word identification with other cognitive functions (e.g., intelligence as expressed by IQ), with reading comprehension or both (for a discussion see Grigorenko, Klin, \& Volkmar, 2003). In fact, it has been noted that the term hyperlexia has been used in different ways by different authors to mark either a superability (i.e., a special talent) or a disability (i.e., indicating a deficient reading comprehension in the face of spared decoding; Grigorenko et al., 2003).

Hyperlexia has been reported in children without autism (Nation, Clarke, \& Snowling, 2002; Snowling \& Frith, 1986), such as individuals with intellectual disability (Cossu, Rossini, \& Marshall, 1993a) or Turner syndrome (Temple \& Carney, 1996). However, there might be a strong correlation between autism and hyperlexia, such that many children with an hyperlexic profile show autism or features of autism (Whitehouse \& Harris, 1984; Healy \& Aram, 1986; Goldberg, 1987; Smith \& Bryson, 1988; Patti \& Lupinetti, 1993; Tirosh \& Canby, 1993; O’Connor \& Hermelin, 1994; Nation \& Snowling, 1999; Grigorenko et al., 2002; Jones et al., 2009).

However, studies on reading skills carried out on larger samples of children with ASD highlighted partially inconsistent results. On one hand, several studies found good levels of decoding both in adults (Rumsey \& Hamburger, 1990), adolescents (Jones et al., 2009), and in children with autism (Frith \& Snowling, 1983; Szatmari, Tuff, Finlayson, \& Bartolucci, 1990; Minshew, Goldstein, Taylor, \& Siegel, 1994; O'Connor \& Hermelin, 1994; Mayes \& Calhoun, 2003; O'Connor \& Klein, 2004; Turkeltaub et al., 2004; Davidson \& Ellis Weismer, 2014); on the other, a few studies reported that poor language skills, typical of the disorder, may predict difficulties in decoding (Tager-Flusberg \& Joseph, 2003; Bishop \& Snowling, 2004; Catts \& Kamhi, 2005).

Language skills play an important role in reading processes, either at basic levels - such as word reading decoding as well as lexical and syntactic analysis - or at higher levels, namely integration and inference between sentences and ideas in the text, monitoring of the comprehension and knowledge of the text structure (Cataldo \& Cornoldi, 1998; Cain \& Oakhill, 1999; Cain, Oakhill, \& Lemmon, 2004). Comprehending is a dynamic process by which new information is integrated with preexisting knowledge (Johnson-Laird, 1983; Gernsbacher, Varner, \& Faust, 1990; Kintsch, 1998). Thus, text comprehension involves both basic cognitive functions, such as syntactic and lexical processing (Nation \& Snowling, 1999), working memory (Carretti, Cornoldi, De Beni, \& Romanò, 2005), and higher cognitive functions, such as comprehension monitoring and awareness of reading purposes and strategies (Yuill \& Oakhill, 1991). Several studies reported these processes to be impaired in individuals with ASD and identified a certain number of deficient functions involved with text comprehension in the same population (for a meta-analysis see Brown, Oram-Cardy, \& Johnson, 2013). In particular, it has been proposed that the status of reading and writing skills reflects deficits in mentalization skills, that is social skills that postulate the ability to "read" the other's mind (Baron-Cohen, 1995), as well as deficits determined by interests in details and consequent difficulties to integrate information (O'Connor \& Klein, 2004; Wahlberg \& Magliano, 2004).

In the literature there are studies mainly based on the comparison of reading skills between individuals with high functioning ASD and children with typical development or studies that compare different subgroups of children with ASD. However, there are several individuals with ASD who show cognitive deficits, particularly borderline intellectual functioning (BIF; Rutter \& Schopler, 1987). By definition, BIF stands on the edge between typical intelligence and intellectual disability, with IQs between 71 and 84 (AAMR, 2002). Only a few studies have focused on the description of learning profiles in this population, although they have reported academic learning difficulties (Capozzi, Musatti, \& Levi, 1991), and impairments in meta-cognitive and meta-language skills (Capozzi, Penge, \& Levi, 1993; Melogno \& Becciu, 1999). Karande, Kanchan, and Kulkarni (2008) analysed academic skills in 55 young persons with BIF (35 males, 20 females), reporting that $89 \%$ of the sample performed poorly, with $25 \%$ showing difficulties in reading. In a study on adolescents with intellectual deficits, Levy (2011) found that the relationship between phonological processing and reading was mediated by IQ; thus, she proposed that learning how to decode is an explicit task that requires general cognitive resources. Overall, there is evidence that general cognitive skills play an important role in reading acquisition in children with intellectual disability or BIF (for a review see Conners, 2003). Nevertheless, children with intellectual disability who read (decode) extremely well have been reported (Cossu et al., 1993a). Furthermore, there is a continuing controversy on the role that intelligence should be given in the case of learning disabilities (e.g., Siegel, 1989) in particular in relationship to the idea of using discrepancy measures to identify children with specific reading deficits (e.g., Stanovich, 2005). Therefore, it seems that general cognitive abilities may play an important role in mediating learning to read but it is uncertain whether this is a general finding or is it specific for children with intellectual 
disability or BIF. Thus, to enucleate the possible role of intelligence in modulating reading difficulties it seems important to properly match children with ASD in terms of general cognitive abilities when evaluating their reading profile.

In the present study, we aimed to examine the reading profile of a group of children with ASD who learnt to read in a language with a very regular orthography, such as Italian. It is well known that orthographic depth has an important modulating role in reading acquisition (e.g., Seymour, Aro, \& Erskine, 2003; Ziegler \& Goswami, 2005). In particular, languages with more irregular orthographies (such as English) may require more phonological proficiency while this may be less compelling in languages with more regular orthographies (Zoccolotti, De Luca, Di Filippo, Judica, \& Martelli, 2009). The mediating role of phonology has been emphasized in the case of children with intellectual disability (Conners, 2003). In the case of children with ASD, the picture is more complex, with some studies reporting spared phonological processing (Frith \& Snowling, 1983; Jones et al., 2009), and others indicating that children with autism may have difficulty in applying phonological decoding strategies (Nation, Clarke, Wright, \& Williams, 2006). In particular, Nation et al. (2006) emphasized the presence of considerable inter-individual variability in children with ASD that may go undetected when only high functioning individuals are examined.

In this study, we separately examined the decoding and comprehension skills of children with ASD who also showed (or not) BIF. Performance of a subgroup of Italian children with ASD/BIF was compared to that of an age-matched group of children with BIF but no signs of ASD. Furthermore, performance of a group of children with ASD and cognitive functioning within normal limits was compared to an individually age-matched group of typically developing children. Our aim was to check whether the reading performance of children with ASD was determined by the presence of autism, by their cognitive level, or by a combination of these factors.

\section{Materials and methods}

\subsection{Participants}

A total of 30 children with ASD participated to the study. The sample was recruited among patients referring to the Diagnostic Clinics of the "Oasi Maria SS" Institute, based in Troina (Italy), specialized in the treatment and rehabilitation of intellectual disability. The ASD subgroup was diagnosed according to DSM-IV-TR (2000), as well as with data derived from the Childhood Autism Rating Scale (C.A.R.S.; Schopler, Reichler, \& Renner, 1988), the Autism Diagnostic Observation Scale (ADOS; Lord, Rutter, Di Lavore, \& Risi, 2005; Italian version by Tancredi et al., 2005) and the Autism Diagnostic InterviewRevised (ADI-R; Rutter, Le Couteur, \& Lord, 2003; Italian version by Faggioli et al., 2005). All children with ASD attended public schools in regular classrooms with the support of a special education teacher.

Out of the total number of individuals with ASD, and based on the performance on the Wechsler Intelligence Scale for Children-III (WISC-III; Wechsler, 1991), 17 children met the criteria for borderline intellectual functioning according to the DSM-IV-TR (2000) criteria, i.e., they all scored below 85 at the FIQ (range VIQ = 55-85, range PIQ =60-89, range FIQ =63-79). Overall, performance was severely impaired both in VIQ (range $=55-85$ ) and in PIQ (range $=60-89$ ). The sample included 15 males and 2 females; their mean age was 9 years and 6 months ( $S D=2.2$, range 7.5-13 years). The subgroups' mean ages and IQ performance are presented in Table 1A. Thirteen children with ASD showed a cognitive performance falling within the normal range. To determine this, we used a lenient criterion, i.e., either a FIQ > 85 and/or at least one scale IQ above

Table 1

Main characteristics of participants. Part A of this table presents results from the comparison between age and intelligence data in ASD/BIF ( $N=17)$ and BIF $(N=22)$ children subgroups. Part B presents age and intelligence data derived from the subgroup of children with ASD and cognitive performances within the normal range $(N=13)$ and the subgroup of typically developing children $(N=16)$; data from the Peabody test were available only for this latter control group (Part B).

\begin{tabular}{|c|c|c|c|c|c|c|c|}
\hline & \multicolumn{3}{|c|}{ ASD/BIF children $(M=15 ; F=2)$} & \multicolumn{3}{|c|}{ BIF children $(M=17 ; F=5)$} & \multirow[b]{2}{*}{$p$} \\
\hline & Mean & SD & Range & Mean & SD & Range & \\
\hline Age & 9.6 & 2.02 & $7.5-13$ & 10.4 & 1.5 & $8.6-13.11$ & .17 \\
\hline Verbal IQ & 70.06 & 8.75 & $55-85$ & 72.45 & 5.07 & $63-84$ & .29 \\
\hline Performance IQ & 74.12 & 9.69 & $60-89$ & 75.41 & 5.11 & $65-86$ & .59 \\
\hline Full IQ & 68.35 & 5.85 & $63-79$ & 71.5 & 3.08 & $63-77$ & $.036^{*}$ \\
\hline \multicolumn{8}{|l|}{ (B) } \\
\hline & \multicolumn{3}{|c|}{ ASD children $(M=11 ; F=2)$} & \multicolumn{3}{|c|}{ Typically developing children $(M=13 ; F=3)$} & \multirow[b]{2}{*}{$p$} \\
\hline & Mean & SD & Range & Mean & SD & Range & \\
\hline Age & 9.2 & 2.32 & $7-13.2$ & 9.9 & 1.5 & $8-13$ & .40 \\
\hline Verbal IQ & 89.77 & 13.2 & $67-107$ & - & - & - & - \\
\hline Performance IQ & 104.08 & 11.03 & $72-115$ & - & - & - & - \\
\hline Full IQ & 96.08 & 7.79 & $82-104$ & - & - & - & - \\
\hline Peabody test & - & - & - & 94.75 & 10.12 & $85-115$ & - \\
\hline
\end{tabular}

$* p<.05$. 
100. Twelve out of thirteen children scored above 85 in FIQ (range $=86-104$ ); the odd one case scored 102 in PIQ and 67 in VIQ (FIQ = 82). Furthermore, twelve children scored above 100 in PIQ (range $=100-115$ ) and four above 100 in VIQ (range =100-107). Therefore, as it might be expected, there was a bias for children to show a higher performance in the PIQ than in the VIQ (mean group difference $=14.3$ ). However, there was one exception with a child performing 104 in VIQ and 72 in PIQ (FIQ = 87). The sample was made of 11 male and 2 female children; their mean age was 9 years and 2 months $(\mathrm{SD}=2.3$, range $7-13.2$ years). The subgroup mean ages and IQ performance are presented in Table $1 \mathrm{~B}$.

The two subgroups of children with ASD were compared to two separate control groups. The children with ASD/BIF were compared to a group of children of the same chronological age with a diagnosis of BIF according to DSM IV-TR (2000), i.e., with a FIQ between 71 and 84. This group included 22 children, 17 males and 5 females with a mean age of 10 years and 4 months ( $S D=1.5$, range 8.6-13.11 years). These were selected among a larger group of children referred to the Oasi Maria SS. Institute for difficulties in school achievements but no additional diagnoses of syndromic type, motor deficits or epilepsy. Children with BIF were then matched individually with children with ASD/BIF on chronological age and IQ(though matching was kept blind to reading performance). Data from the subgroup of children with BIF are presented in Table $1 \mathrm{~A}$. ASD/BIF and BIF subgroups did not differ for chronological age $\left(t_{(37)}=-1.41, p=.17\right.$, Cohen's $d=.45$; see Table $\left.1 \mathrm{~A}\right)$. As expected based on the selection procedure, the two subgroups did not differ for VIQ $\left(t_{(37)}=-1.07, p=.29\right.$, Cohen's $\left.d=.35\right)$ and PIQ $\left(t_{(37)}=-.54\right.$, $p=.59$, Cohen's $d=.29$ ). However, a small (about 3 points) albeit reliable $\left(t_{(37)}=-2.16, p=.03\right.$, Cohen's $\left.d=.71\right)$ difference was found in FIQ, with performance being higher in children with BIF than in children with ASD/BIF (see Table 1A).

Children with ASD and cognitive performance within normal limits were compared with a second control group of 16 typically developing children, 13 males and 3 females, with a mean age of 9 years and 9 months (SD =1.5, range 8-13 years). These children were selected from local public schools located in the same area; they showed no signs of motor or cognitive disability. They were matched individually with children with ASD on chronological age and gender before measuring reading performances. The two groups did not differ for chronological age $\left(t_{(27)}=-.98, p=.40\right.$, Cohen's $d=.35$; see Table 1B). Only for this control subgroup, additional data from the PPVT-R Peabody Test were also available (Dunn \& Dunn, 1981; Italian version and norms by Stella, Pizzoli, \& Tressoldi, 2000): mean performance of receptive vocabulary turned out to fall within expected limits for these children (see Table 1B).

Informed consent was obtained from all participants to the study.

\subsection{Reading assessment}

To assess decoding skills (accuracy and speed) we used tests requiring the reading of words and pseudo-words as well as meaningful texts, which are standardized for Italian children, thus providing norms for the critical ages of our children.

The Word and Pseudo-word Reading subtests from the Battery for the Assessment of Developmental Reading and Spelling Disorders (Sartori, Job, \& Tressoldi, 1995) were administered following the standard procedure. These subtests assess speed and accuracy while reading a list of 112 words (four sets of 28 words varying for frequency and imageability) and a list of 48 pseudo-words (three sets of 16 pseudo-words). Errors and reading speed were scored. Reading speed was measured dividing the total number of words read by the total time spent for reading, expressed in seconds; reading accuracy was assessed by counting the number of words incorrectly decoded. Test-retest reliability coefficients are reported as .80 for speed and .71 for accuracy (Sartori et al., 1995). Since groups included children from different grades, individual raw data were converted into $z$ scores based on normative data (Sartori et al., 1995). In all the cases, positive values indicate better performances (i.e., fewer errors and higher speed), whereas negative values are indicative of lower performances.

The Text Reading task from the M.T. Reading Battery for Primary School (Cornoldi \& Colpo, 1998) was administered following the standard procedure. In this test, the child is required to read a text passage aloud within a 4-min time limit; reading speed (total number of syllables divided by the total time spent, expressed in seconds) and accuracy (number of errors, adjusted for the amount of text read) are scored. In scoring accuracy, errors, self-corrections, long pauses (above $5 \mathrm{~s}$ ), and repetitions are given full ( 1 error) or partial ( $1 / 2$ error) credit. Texts vary depending on the child's school grade. Testretest reliability coefficients are reported as ranging from .75 to .87 for accuracy and from .94 to .97 for speed depending on grade level (Cornoldi \& Colpo, 1998). Raw data were converted into $z$-scores based on normative data (Cornoldi \& Colpo, 1998). In all cases, positive values indicate better performance, while negative values are indicative of lower performance.

In order to assess reading comprehension, the Comprehension task from the M.T. Reading Battery for Primary School (Cornoldi \& Colpo, 1998) was used. The child is required to read a text silently and check it subsequently during the answering phase. There are 10 multiple-choice questions. The total number of correct responses is the measure of performance. Texts vary depending on the child's school grade. Test-retest reliability coefficients are reported between .70 and .75 depending on grade level (Cornoldi \& Colpo, 1998). Raw data were converted into $z$-scores based on normative data (Cornoldi \& Colpo, 1998), with positive values indicating better performance.

\section{Results}

\subsection{Comparison between children with ASD/BIF and children with BIF}

A MANOVA, with group (ASD/BIF vs. BIF) as between-subjects measure and reading measure (accuracy vs. speed) as repeated measure, was carried out on the standardized, age-adjusted scores from the Text reading subtest of the M.T. Reading 
Table 2

Mean performance (and SDs) in the reading tasks for children with ASD/BIF and children with BIF. An asterisk marks the performance for the conditions which significantly deviate from normative values (i.e., mean $=0$ ) with at least $p<.05$. Percentages of children with pathological performance (i.e., a score at least 1.65 SD below the means of the respective norms) are presented separately for each group.

\begin{tabular}{|c|c|c|c|c|c|c|c|}
\hline & & \multicolumn{3}{|c|}{ Children with ASD and BIF } & \multicolumn{3}{|c|}{ Children with BIF } \\
\hline & & Mean & SD & Mean & SD & Mean & SD \\
\hline \multirow[t]{2}{*}{ Text reading } & Accuracy & -.03 & 1.76 & 5.9 & $-1.31^{*}$ & 1.71 & 40.9 \\
\hline & Speed & -.57 & 1.18 & 17.6 & $-1.69^{*}$ & .77 & 50.0 \\
\hline \multirow[t]{2}{*}{ Word reading } & Accuracy & -.40 & 1.83 & 11.8 & $-1.97^{*}$ & 2.06 & 45.5 \\
\hline & Speed & -.42 & 1.22 & 23.5 & $-1.65^{*}$ & 1.06 & 54.5 \\
\hline \multirow[t]{2}{*}{ Pseudo-word reading } & Accuracy & -.26 & 1.84 & 0 & $-1.66^{*}$ & 1.90 & 54.5 \\
\hline & Speed & .18 & 1.94 & 11.8 & $-.94^{*}$ & .91 & 13.6 \\
\hline Text comprehension & Accuracy & $-1.28^{*}$ & .70 & 29.4 & $-1.41^{*}$ & .94 & 45.5 \\
\hline
\end{tabular}

* Significantly different from normative values (i.e., mean $=0$ ) with at least $p<.05$.

Battery (Cornoldi \& Colpo, 1998). Relevant means for this analysis are reported in Table 2. The group effect was significant $\left[F_{(1,37)}=11.62, p<.01\right.$; partial eta $\left.^{2}=.24\right]$, thus indicating better performances in children with ASD/BIF $(-.39)$ than in children with BIF ( -1.50$)$. Neither the reading measure effect [Wilks $\lambda=.934, F_{(1,37)}=2.63, p=.11$; partial eta ${ }^{2}=.07$ ], nor the reading measure by group interaction [Wilks $\lambda=.998, F_{(1,37)}=.81, p=.78$; partial eta ${ }^{2}=.002$ ] turned out to be significant.

A MANOVA, with group (ASD vs. BIF) as between-subjects measure and lexicality (words vs. pseudo-words) and reading measure (accuracy vs. speed) as repeated measures, was carried out on the standardized, age-adjusted scores from the Word and Pseudo-word Reading subtests (see relevant means in Table 2). The analysis indicated the main effect of lexicality [Wilks $\lambda=.807, F_{(1,37)}=8.82, p<.01$; partial eta ${ }^{2}=.19$ ], with lower performances for words $(-1.11)$ than pseudo-words $(-.67)$. Neither the reading measure effect [Wilks $\lambda=.956, F_{(1,37)}=1.68, p=.20$; partial eta ${ }^{2}=.04$ ], nor the lexicality by reading measure interaction [Wilks $\lambda=.934, F_{(1,37)}=2.60, p=.11$; partial eta ${ }^{2}=.07$ ] turned out to be significant. The group effect was significant $\left[F_{(1,37)}=10.96, p<.01\right.$; partial eta $\left.{ }^{2}=.23\right]$, thus indicating better performances in children with ASD/BIF $(-.22)$ than in children with BIF (-1.55). All interactions involving the group factor were far from significance.

Since performance was expressed as $z$-converted values with respect to established norms, it was also possible to compare performance in separate conditions with the norms by means of one-sample $t$ tests (with 0 as the expected mean). All means of children with ASD/BIF did not significantly differ from norms (all $p s>.05$ ), unlike those of children with BIF, which significantly deviated from expected values (at least $p<.05$; see Table 2 ).

Table 2 also reports the proportion of children for each group showing a pathological performance, with -1.65 below the mean being the cut-off point (assuming a normal distribution, it marks a performance below which about 5\% of cases are expected). Percentages of pathological performance were found to be generally low in children with ASD/BIF (ranging from 0 to $23.5 \%$ depending on the reading condition; median: $11.8 \%$ ). By contrast, in about half of the cases, children with BIF were pathological across text and word conditions, except for speed in reading pseudo-words, where a decreased proportion was observed. However, analysis of individual data indicated large inter-individual variability in this subgroup of children. For example, 2 to 10 children showed a performance within half SD from the norms (or higher), depending on the reading condition used. This indicates that in $9.1 \%$ to $45.4 \%$ of cases performance was fully normal (median across conditions: $25.0 \%$ ).

At the Comprehension task from the M.T. Reading Battery for Primary School (Cornoldi \& Colpo, 1998), the two groups of children did not significantly differ from one another $\left(t_{(37)}=.48, p=.64\right.$; Cohen's $\left.d=.16\right)$. However, they both significantly deviated from norms (at least $p<.05$; see Table 2 ). A pathological performance was present in $45.5 \%$ of children with BIF and in $29.4 \%$ of children with ASD/BIF.

\subsection{Summary of results}

Children with ASD/BIF showed generally spared decoding skills: their mean performance did not significantly deviate from the norms across reading tasks (text and word/pseudo word reading) and measures (accuracy and speed), and only a few instances of impaired performance were detected. These children also showed overall better performance than children matched on intellectual abilities, i.e., children with BIF without ASD. Notably, no selective effect was detected in terms of stimulus materials, i.e., children with BIF were similarly impaired in reading words and pseudo-words. Indeed, an unexpected trend for lower scores in words than pseudo-words reading was detected, but it was general and did not interact with group.

As a group, children with BIF were slower and less accurate readers, though considerable inter-individual variation was also present. Indeed, these children showed the full range of possible performance: namely, in about half of cases, performance was severely impaired, in a few was moderately deficient, and in about one fourth was fully within normal limits. As for text comprehension, both groups of children deviated from the norms and deficiencies were rather similar for the two groups.

Overall, at least in terms of a group trend, the profile of children with ASD/BIF was consistent with the diagnosis of hyperlexia, where decoding is slightly or not impaired at all, unlike reading comprehension. By contrast, reading performance impairments (deficient decoding and comprehension) were rather homogeneously distributed in the group of children with BIF. 
Table 3

Mean performance (and SDs) in the reading tasks for children with ASD and cognitive performances within the normal range and for the typically developing children. An asterisk marks the performance for the conditions which significantly deviate from normative values (i.e., mean $=0$ ) with at least $p<.05$. Percentages of children with pathological performance (i.e., a score at least 1.65 SD below the means of the respective norms) are presented separately for each group.

\begin{tabular}{|c|c|c|c|c|c|c|c|}
\hline & & \multicolumn{3}{|c|}{ Children with ASD } & \multicolumn{3}{|c|}{ Typically developing children } \\
\hline & & Mean & SD & $\%$ pathol. & Mean & SD & $\%$ pathol. \\
\hline \multirow[t]{2}{*}{ Text reading } & Accuracy & -.03 & 1.24 & 15.4 & .73 & .59 & 0 \\
\hline & Speed & -.06 & .46 & 23.1 & .41 & .81 & 0 \\
\hline \multirow[t]{2}{*}{ Word reading } & Accuracy & -.46 & 1.83 & 23.1 & .27 & .64 & 0 \\
\hline & Speed & .4 & 2.1 & 0 & 1 & 1.01 & 0 \\
\hline \multirow[t]{2}{*}{ Pseudo-word reading } & Accuracy & -.15 & 1.26 & 7.7 & .52 & .6 & 0 \\
\hline & Speed & 1.12 & 2.6 & 0 & .78 & .96 & 0 \\
\hline Text comprehension & Accuracy & $-.69^{*}$ & .92 & 15.4 & 0 & .69 & 0 \\
\hline
\end{tabular}

\subsection{Comparison between children with ASD and typically developing children}

A MANOVA, similar to that presented above, was carried out on the scores from the Text reading subtest from the M.T. Reading Battery (Cornoldi \& Colpo, 1998). Relevant means for this analysis are reported in Table 3. The group effect was significant $\left[F_{(1,37)}=5.49, p<.05\right.$; partial eta $\left.{ }^{2}=.17\right]$, thus indicating better performances in typically developing $(.53)$ than in children with ASD (-.11). The reading measure effect showed only a slight trend [Wilks $\lambda=.879, F_{(1,27)}=3.70, p=.065$; partial eta ${ }^{2}=.12$ ] for higher values in accuracy (.36) than reading speed (.05). The reading measure by group interaction [Wilks $\lambda=.977, F_{(1,37)}=.64, p=.54$; partial eta ${ }^{2}=.02$ ] was not significant.

The MANOVA on the scores from the Word and Pseudo-word Reading subtests indicated the main effect of lexicality [Wilks $\lambda=.775, F_{(1,27)}=7.83, p<.01$; partial eta ${ }^{2}=.22$ ], with lower performances for words $(.27)$ than pseudo-words (.61). The reading measure effect was significant [Wilks $\lambda=.738, F_{(1,27)}=9.60, p<.01$; partial eta ${ }^{2}=.26$ ], thus indicating better performances in reading speed (.83) than accuracy (.05). The lexicality by reading measure interaction was not significant [Wilks $\lambda=.999, F_{(1,27)}=.03, p=.87$; partial eta $\left.{ }^{2}=.001\right]$. Neither the group effect $\left[F_{(1,27)}=.84, p=.37 ; p\right.$ partial eta $\left.{ }^{2}=.03\right]$ nor the totality of interactions involving the group factor turned out to be significant.

When performance in separate conditions was checked by means of one-sample $t$ tests (with 0 as the expected mean), none of the means of both children with ASD and typically developing children significantly deviated from the norms (see Table 3 ).

Table 3 also reports the proportion of children for each group showing a pathological performance (cut-off: -1.65 ). Percentages of pathological performance were generally low among children with ASD (ranging from 0 to $23.1 \%$; median: $11.5 \%$ ). None of the typically developing children showed a pathological performance in any of the conditions.

On the Comprehension task from the M.T. Reading Battery, children with ASD scored significantly lower than typically developing children $\left(.69 ; t_{(27)}=-2.57, p=.01\right.$; Cohen's $\left.d=.86\right)$, and their performance $(-.69)$ significantly deviated from the norms ( $p<.05$; see Table 3$)$. A pathological performance was found in $15.4 \%$ of children with ASD and in none of the typically developing children.

\subsection{Summary of results}

Again, results indicate generally spared decoding skills in children with ASD and cognitive performance within normal limits: their mean performance did not significantly deviate from the norms across reading tasks and measures. Furthermore, only a small (although not zero) proportion of children showed impaired performance with respect to normative values. Their performance was comparable to that of age-matched typically developing children in word and pseudo-word reading. A small but reliable difference was observed for text reading with a somewhat lower performance for ASD than controls (with a difference of ca. 6 standard points).

Data on text comprehension indicated an impairment in children with ASD and cognitive performance within normal limits with regard to both the norms and the group of age-matched controls.

Once again, the profile of children with ASD turned out to be consistent with the diagnosis of hyperlexia, with largely spared (or minimally impaired) decoding and impaired reading comprehension.

\section{Discussion}

Results of this study indicate that the reading performance in children with ASD depends more upon the presence of the pathological condition and less upon the cognitive level per se. In fact, as a group, performance profiles were characterized by a dissociation between decoding (largely spared) and comprehending (deficient) a written text, both in the case of children with ASD and BIF, as well as in the case of children with ASD and cognitive performance within normal limits. Therefore, children with ASD can develop efficient decoding in spite of their limited expertise in linguistic skills. Indeed, some authors noted a compulsive interest in reading at the expense of other communication means (Elliot \& Needleman, 1976; Huttenlocher \& Huttenlocher, 1973; Mehegan \& Dreifuss, 1972). This pattern is consistent with the idea proposed by some 
authors that reading decoding represents an encapsulated module which is largely independent from other linguistic skills (e.g., Cossu, Rossini, \& Marshall, 1993b).

Spared decoding along with deficient comprehension is referred to as hyperlexia (Silberberg \& Silberberg, 1967). As stated in the introduction, several authors see this condition as being either a special talent or a selective disability in reading comprehension (Grigorenko et al., 2003). The dissociation between cognitive level and reading decoding observed here adds up information to this debate; in particular, spared decoding appears to be as a superability, to the extent in which it appreciably surpasses the general cognitive skills at least in children with ASD/BIF. The comparison with children with BIF showing no autistic signs is particularly informative here. The performance of this subgroup showed more consistent deficiencies across different domains, with deficits in reading decoding, reading comprehension, as well as verbal and nonverbal intellectual skills. This pattern is consistent with previous reports on these children (Conners, 2003). However, it should also be acknowledged that the performance of this group of children was highly variable, with several children performing within normal limits. The presence of exceptional children with intellectual disability but spared decoding ability has been reported (Cossu et al., 1993b), although it is still unclear which factors over and beyond intelligence can account for these individual differences.

These results, obtained in a language with a highly regular orthography like Italian, are generally consistent with previous reports on languages with a highly irregular orthography, such as English (Aaron, Frantz, \& Manges, 1990; Perfetti, 1985; Stothard \& Hulme, 1996; Minshew et al., 1994; O’Connor \& Klein, 2004; Catts \& Kamhi, 2005; Huemer \& Mann, 2010). It may be added that there are a few recent case reports of children with hyperlexia reading Spanish (Talero-Gutierrez, 2006) and Swedish (Asberg \& Miniscalco, 2014), two languages with relatively regular orthographies. Therefore, it seems that the sparing of decoding ability in children with ASD may occur independent from the orthographic depth of the language. In languages with less transparent orthographies, and in particular in English, some authors (Nation et al., 2006) emphasized the modulating role of phonological skills. In this study we examined performance in both words and pseudo-words reading, obtaining largely similar results. These findings indicate that children with ASD can effectively decode letters strings based on the application of grapheme-to-phoneme conversion (and presumably in the absence of lexical support). Therefore, there is no indication in the present data for the possible critical role of phonological skills in mediating reading in children with ASD as reported for English (Nation et al., 2006).

In spite of spared decoding skills, children with ASD show a selective deficit in reading comprehension, irrespective of the presence of BIF. This deficiency has important implications for their academic achievements and calls for active intervention. A recent meta-analysis (El Zein, Solis, Vaughn, \& McCulley, 2014) indicates that cognitive and metacognitive interventions focusing on strategy instruction, student grouping practices, and explicit instruction appear to have a positive impact on the reading comprehension of students with ASD. These programs offer important cues to help educators in optimizing teaching to students with ASD.

This study has a number of limitations. In particular, to reliably place the performance of our children in relation to consolidated normative values, we opted for the use of standardized clinical instruments for the analysis of reading and focused on a group analysis of the performance of children with ASD. Since the presence of individual differences was rather evident, in future studies it seems important to use experimental measures that would allow more exhaustive descriptions of individual children's profiles (for a discussion on this issue, see Mervis \& Klein-Tasman, 2004). Furthermore, because of time limitations, this study focused only on reading measures. While children were assessed with basic instruments testing autistic symptoms, it would certainly be useful to administer a comprehensive battery assessing their language functioning. In particular, this would enable the investigation of the relationship between children's reading comprehension deficits and language skills. In comparing groups with pathological performance, it is comparatively difficult to obtain perfectly matched groups. In particular, ASD/BIF and BIF subgroups did not differ on VIQ and PIQ but a small difference was detected in the case of FIQ, with children with BIF scoring higher than children with ASD/BIF. However, as children with ASD/BIF performed better (not worse) in reading, it seems unlikely that this small IQ difference is responsible for the pattern of results obtained. Finally, due to time limitations, information on children with typical development was limited to their receptive vocabulary skills; in future investigations, a more comprehensive evaluation of the cognitive ability of the control group would certainly strengthen the value of the results.

\section{Conclusion}

Italian children with ASD (whether with or without BIF) showed essentially spared decoding skills in text, word and pseudo-word reading, and a selective impairment in reading comprehension, just like children with BIF but unlike typically developing children. Therefore, reading performance in children with ASD was related more to the presence of the pathological condition, and less to children's overall cognitive level. These results are generally consistent with a profile of hyperlexia for children with ASD learning a regular orthography, as previously reported for languages with a more irregular orthography.

\section{Ethical approval}

This study was approved by the Ethical Committee of the Research Institute "IRCCS Associazione Oasi Maria SS.", Troina (EN), Italy. 


\title{
Conflict of interest statement
}

\author{
The authors declare they have no conflicts of interest to disclose.
}

\section{Acknowledgement}

\section{This research was funded by the Italian Ministry of Health.}

\section{References}

Aaron, P. G., Frantz, S. S., \& Manges, A. R. (1990). Dissociation between comprehension and pronunciation in dyslexic and hyperlexic children. Reading and Writing, 2, 243-264

American Association on Mental Retardation (2002). Mental retardation: Definition, classification and systems of supports (10th ed.). Washington DC: Author. American Psychiatric Association (2000). DSM-IV-TR. Diagnostic and statistical manual of mental disorders (4th ed.). Washington, DC: American Psychiatric Association (Trad. it. (2001). Manuale diagnostico e statistico dei disturbi mentali. Text Revision. DSM-IV-TR. Milano: Masson).

Asberg, J., \& Miniscalco, C. (2014). Excellent word-reading ability in the context of an autism spectrum disorder: A case study of a Swedish-speaking 7-year-old boy. Journal of Cognitive Education and Psychology, 13(1), 88-102.

Baron-Cohen, S. (1995). Mindblindness: An essay on autism and theory of mind. Cambridge, MA: MIT Press/Bradford Books.

Bartak, L., Rutter, M., \& Cox, A. (1975). A comparative study of infantile autism and specific development receptive language disorder I. The children. British Journal of Psychiatry, 126, 127-145.

Bishop, D. V. M., \& Snowling, M. J. (2004). Developmental dyslexia and specific language impairment: Same or different? Psychological Bulletin, 130 , 858-886.

Brown, H. M., Oram-Cardy, J., \& Johnson, A. (2013). A meta-analysis of the reading comprehension skills of individuals on the autism spectrum. Journal of Autism and Developmental Disorders, 43, 932-955.

Cain, K., \& Oakhill, J. V. (1999). Inference making and its relation to comprehension failure. Reading and Writing, 11, 489-503.

Cain, K., Oakhill, J. V., \& Lemmon, K. (2004). Individual differences in the inference of word meanings from context: The influence of reading comprehension, vocabulary knowledge, and memory capacity. Journal of Educational Psychology, 96, 671-681.

Capozzi, F., Musatti, L., \& Levi, G. (1991). I disturbi di apprendimento nel ritardo mentale. In C. Cornoldi (Ed.), I disturbi dell'Apprendimento. Aspetti psicologici e neuropsicologici (pp. 169-188). Bologna: Il Mulino.

Capozzi, F., Penge, R., \& Levi, G. (1993). I conflitti logico-linguistici nei bambini borderline cognitivi. In G. Masi \& A. Martini (Eds.), Apprendimento e patologia neuropsichica nei primi anni di scuola (pp. 52-60). Rome: Borla.

Carretti, B., Cornoldi, C., De Beni, R., \& Romanò, M. (2005). Updating in working memory: A comparison of good and poor comprehenders. Journal of Experimental Child Psychology, 91, 45-66.

Cataldo, G., \& Cornoldi, C. (1998). Self-Monitoring in poor and good reading comprehenders and their use of strategy. British Journal of Developmental Psychology, $16,155-165$

Catts, H. W., \& Kamhi, A. G. (2005). The connections between language and reading disabilities. London: Lawrence Erlbaum.

Conners, F. A. (2003). Reading skills and cognitive abilities of individuals with mental retardation. International Review of Research in Mental Retardation, 27, $191-229$.

Cornoldi, C., \& Colpo, G. (1998). Prove di Lettura MT per la Scuola Elementare-2. Firenze: OS Organizzazioni Speciali.

Cossu, G., Rossini, F., \& Marshall, J. C. (1993a). When reading is acquired but phonemic awareness is not: A study of literacy in Down syndrome. Cognition, 46, $129-138$.

Cossu, G., Rossini, F., \& Marshall, J. C. (1993b). Reading is reading is reading. Cognition, 48, 297-302.

Courchesne, E., Lincoln, A. J., Yeung-Courchesne, R., Elmasian, R., \& Grillon, C. (1989). Pathophysiologic findings in nonretarded autism and receptive developmental language disorder. Journal of Autism and Developmental Disorders, 19, 1-17.

Davidson, M. M., \& Ellis Weismer, S. (2014). Characterization and prediction of early reading abilities in children on the autism spectrum. Journal of Autism and Developmental Disorders, 44(4), 828-845.

Dunn, L. M., \& Dunn, L. M. (1981). Peabody picture vocabulary test-revised. Minnesota: American Guidance Service (Italian version by Stella, G., Pizzoli, C., \& Tressoldi, P.E. (2000). PPVT-R. Il Peabody Test. Test di vocabolario recettivo.).

El Zein, F., Solis, M., Vaughn, S., \& McCulley, L. (2014). Reading comprehension interventions for students with autism spectrum disorders: A synthesis of research. Journal of Autism and Developmental Disorders, 44(4), 1303-1322.

Elliot, D. E., \& Needleman, R. M. (1976). The syndrome of hyperlexia. Brain and Language, 3, 339-349.

Frith, U., \& Snowling, M. (1983). Reading for meaning and reading for sound in autistic and dyslexic children. British Journal of Developmental Psychology, 1 , 329-342.

Gernsbacher, M. A., Varner, K. R., \& Faust, M. E. (1990). Investigating differences in general comprehension skill. Journal of Experimental Psychological Learning Memory \& Cognition, 16, 430-445.

Goldberg, T. E. (1987). On hermetic reading abilities. Journal of Autism and Developmental Disorders, 17, 29-44

Grigorenko, E. L., Klin, A., Pauls, D. L., Senft, R., Hooper, C., \& Volkmar, F. (2002). A descriptive study of hyperlexia in a clinically referred sample of children with developmental delays. Journal of Autism and Developmental Disorders, 32, 3-12.

Grigorenko, E. L., Klin, A., \& Volkmar, F. (2003). Annotation: Hyperlexia: Disability or superability? Journal of Child Psychology and Psychiatry and Allied Disciplines, 44, 1079-1091.

Healy, D. M., \& Aram, J. M. (1986). Hyperlexia and dyslexia: A family study. Annals of Dyslexia, 36, $237-252$.

Huemer, S. V., \& Mann, V. (2010). A comprehensive profile of decoding and comprehension in autism spectrum disorders. Journal of Autism and Developmental Disorders, 40, 483-485.

Huttenlocher, P. R., \& Huttenlocher, J. (1973). A study of children with hyperlexia. Neurology, 23, 1107-1116.

Johnson-Laird, P. N. (1983). Mental models. Cambridge, England: Cambridge University Press.

Jones, C. R., Happé, F., Golden, H., Marsden, A. J., Tregay, J., Simonoff, E., et al. (2009). Reading and arithmetic in adolescents with autism spectrum disorders: Peaks and dips in attainment. Neuropsychology, 23(6), 718-728.

Kanner, L. (1943). Autistic disturbances of affective contact. Nervous Child, 2, 217-250.

Kanner, L. (1946). Irrelevant and metaphorical language. American Journal of Psychiatry, 103, 242-246.

Karande, S., Kanchan, S., \& Kulkarni, M. (2008). Clinical and psychoeducational profile of children with borderline intellectual functioning. Indian Journal of Pediatrics, 75, 795-800.

Kintsch, W. (1998). Comprehension: A paradigm for cognition. Cambridge, UK: University Press.

Levy, Y. (2011). IQ predicts word decoding skills in populations with intellectual disabilities. Research in Developmental Disabilities, 32, $2267-2277$.

Lord, C., Rutter, M., Di Lavore, P. C., \& Risi, S. (2005). Autism diagnostic observation schedule (ADOS). Los Angeles, CA: Western Psychological Services (Italian version by Tancredi, R., Saccani, M., Persico, A. M., Parrini, B., Igliozzi, R. and Faggioli, R. (2005). Florence: Organizzazioni Speciali.).

Mayes, S. D., \& Calhoun, S. L. (2003). Ability profiles in children with autism: Influence of age and IQ. Autism, 7, 65-80.

Mehegan, C. C., \& Dreifuss, F. E. (1972). Hyperlexia Exceptional reading ability in brain-damaged children. Neurology, $22,1105-1111$. 
Melogno, S., \& Becciu, M. M. (1999). Comprensione metaforica e consapevolezza metalinguistica nei bambini borderline cognitivi. Psichiatria dell'Infanzia e dell'Adolescenza, 64, 707-716.

Mervis, C. B., \& Klein-Tasman, B. P. (2004). Methodological issues in group-matching designs: $\alpha$ levels for control variable comparisons and measurement characteristics of control and target variables. Journal of Autism and Developmental Disorders, 34, 7-17.

Minshew, N. J., Goldstein, G., Taylor, H. G., \& Siegel, D. J. (1994). Academic achievement in high functioning autistic individuals. Journal of Clinical and Experimental Neuropsychology, 16, 261-270.

Nation, K., \& Snowling, M. (1999). Developmental differences in sensitivity to semantic relations among good and poor comprehenders: Evidence from semantic priming. Cognition, 19, B1-B13.

Nation, K., Clarke, P., \& Snowling, M. J. (2002). General cognitive ability in children with poor reading comprehension. British Journal of Educational Psychology, 72, 549-560.

Nation, K., Clarke, P., Wright, B., \& Williams, C. (2006). Patterns of reading ability in children with autism spectrum disorder. Journal of Autism and Developmental Disorders, 36, 911-919.

O'Connor, N., \& Hermelin, B. (1994). Two autistic savant readers. Journal of Autism and Developmental Disorders, 24, $501-515$.

O'Connor, I. M., \& Klein, P. D. (2004). Exploration of strategies for facilitating the reading comprehension of high-functioning students with autism spectrum disorders. Journal of Autism and Developmental Disorders, 34, 115-127.

Parker, S. W. (1919). Pseudo-talent for words. Psychology Clinics, 11, 1-7.

Patti, P. J., \& Lupinetti, L. (1993). Brief report: Implications of hyperlexia in an autistic savant. Journal of Autism and Developmental Disorders, $23,397-405$.

Perfetti, C. A. (1985). Reading ability. Oxford: Oxford University Press.

Phillips, A. (1930). Talented imbeciles. Psychology Clinics, 18, 246-265.

Rumsey, J. M., \& Hamburger, S. D. (1990). Neuropsychological divergence of high-level autism and severe dyslexia. Journal of Autism and Developmental Disorders, 20, 155-168.

Rutter, M., \& Schopler, E. (1987). Autism and pervasive developmental disorders: Concepts and diagnostic issues. Journal of Autism and Developmental Disorders, 17, $159-186$.

Rutter, M., Le Couteur, A., \& Lord, C. (2003). Autism diagnostic interview-Revised. Los Angeles, CA: Western Psychological Services (Italian version by Faggioli, R., Saccani, M., Persico, A. M., Tancredi, R., Parrini, B., \& Igliozzi, R. (2005). Florence: Organizzazioni Speciali.).

Rutter, M. (1983). Cognitive deficits in the pathogenesis of autism. Journal of Child Psychology and Psychiatry, 24, 513-531.

Sartori, G., Job, R., \& Tressoldi, P. E. (1995). Batteria per la Valutazione della Dislessia e della Disortografia Evolutiva. Firenze: Organizzazioni Speciali.

Schopler, E., \& Mesibov, G. B. (1995). Learning and cognition in autism. In 12th annual TEACCH conference, "Learning and Cognition in Autism". Chapel Hill, NC: Plenum Press.

Schopler, E., Reichler, R. J., \& Renner, B. R. (1988). The Childhood Autism Rating Scale (CARS). Los Angeles, CA: Western Psychological Service Inc.

Seymour, P. H., Aro, M., \& Erskine, J. M. (2003). Foundation literacy acquisition in European orthographies. British Journal of Psychology, $94,143-174$.

Siegel, L. S. (1989). IQ is irrelevant to the definition of learning disabilities. Journal of Learning Disabilities, 22, 469-478.

Sigman, M., \& Mundy, P. (1987). Symbolic processes in young autistic children. New Directions for Child and Adolescent Development, $36,31-46$.

Silberberg, N., \& Silberberg, M. (1967). Hyperlexia: Specific word recognition skills in young children. Exceptional Child, $34,41-42$.

Silberberg, N. E., \& Silberberg, M. C. (1968-1969). Case histories in hyperlexia. Journal of School Psychology, 7, 3-7.

Smith, I. M., \& Bryson, S. E. (1988). Monozygotic twins concordant for autism and hyperlexia. Developmental Medicine and Child Neurology, $30,527-535$.

Snowling, M., \& Frith, U. (1986). Comprehension in hyperlexic readers. Journal of Experimental Child Psychology, 42, $392-415$.

Stanovich, K. E. (2005). The future of a mistake: Will discrepancy measurement continue to make the learning disabilities field a pseudoscience? Learning Disability Quarterly, 28(2), 103-106.

Stothard, S. E., \& Hulme, C. (1996). A comparison of reading comprehension and decoding difficulties in children. In C. Cornoldi \& J. Oakhill (Eds.), Reading comprehension difficulties. Processes and intervention (pp. 93-112). Mahwah, NJ: Erlbaum.

Szatmari, P., Tuff, L., Finlayson, M. A., \& Bartolucci, G. (1990). Asperger's syndrome and autism: Neurocognitive aspects. Journal of the American Academy of Child and Adolescent Psychiatry, 29, 130-136.

Tager-Flusberg, H., \& Joseph, R. M. (2003). Identifying neurocognitive phenotypes in autism. Philosophical Transactions of the Royal Society of London Series BBiological Sciences, 358, 303-314.

Talero-Gutierrez, C. (2006). Hyperlexia in Spanish-speaking children: Report of 2 cases from Colombia, South America. Journal of the Neurological Sciences, 249, 39-45.

Temple, C. M., \& Carney, R. (1996). Reading skills in children with Turner's syndrome: An analysis of hyperlexia. Cortex, 32, $335-345$.

Tirosh, E., \& Canby, J. (1993). Autism with hyperlexia: A distinct syndrome? American Journal of Mental Retardation, 98, 84-92.

Turkeltaub, P. E., Flowers, D. L., Verbalis, A., Miranda, M., Gareau, L., \& Eden, G. F. (2004). The neural basis of hyperlexic reading: An fMRI case study. Neuron, 41, $11-25$.

Wahlberg, T., \& Magliano, J. P. (2004). The ability of high function individuals with autism to comprehend written texts. Discourse Processes, 38, 119-144.

Wechsler, D. (1991). WISC-III. Wechsler Intelligence Scale for Children-III. New York: The Psychological Corporation (It. Transl. by Orsini, A., \& Picone L. 2006. Firenze: O.S. Organizzazioni Speciali.).

Whitehouse, D., \& Harris, J. C. (1984). Hyperlexia in infantile autism. Journal of Autism and Developmental Disorders, 14, $281-289$.

Yuill, N., \& Oakhill, J. (1991). Children's problems in text comprehension. An experimental investigation. Cambridge, UK: Cambridge University Press.

Ziegler, J. C., \& Goswami, U. (2005). Reading acquisition, developmental dyslexia, and skilled reading across languages: A psycholinguistic grain size theory. Psychological Bulletin, 131, 3-29.

Zoccolotti, P., De Luca, M., Di Filippo, G., Judica, A., \& Martelli, M. (2009). Reading development in an orthographically regular language: Effects of length, frequency, lexicality and global processing ability. Reading and Writing, 22, 1053-1079. 